\title{
Relato corto
}

\section{Epidemias}

\section{José Alcami Pertejo}

Profesor de Investigación del Centro Nacional de Microbiología, Instituto de Salud Carlos III; ppalcami@isciii.es

El busca vibró como un escarabajo siniestro mientras contemplaba una rojiza puesta de sol sobre los bloques de la meseta de Orcasitas. Se encontraba en su despacho de la planta 12 de aquel hospital que llevaba el mismo número en su DNI. Aquel aviso no presagiaba nada bueno porque tras silenciarlo el buscapersonas volvió a sonar sin un respiro. Era el código de una urgencia vital. Jaime Sender, residente con muchas guardias a sus espaldas, corrió hacia el interfono más cercano y marcó el 9. Sin preguntar quién era, la voz de centralita respondió apresurada un código: 14, 34,1.

Corrió por los pasillos grises, subió de dos en dos los peldaños curtidos de grietas y en un minuto se encontraba en la planta 14 ante la puerta de la habitación 34. Nunca había visto el espectáculo dantesco que se le echó encima al abrir la puerta. El paciente, un joven con una palidez extrema y amarillenta boqueaba mientras la enfermera intentaba inútilmente ventilarle con un ambú. La sangre pintaba de cortinajes churretosos toda la habitación, las paredes, el suelo, hasta el techo, y por supuesto a las dos enfermeras que intentaban reanimar al paciente.

Se acercó para ayudarlas cuando aquel sujeto se arqueó como un gusano, abrió unos ojos enloquecidos y le lanzó al cuello una garra que empezó a ahogarle con una fuerza inesperada. Entonces todo explotó, porque fue como el estallido de un globo lleno de sangre que empezó a brotar por el tubo endotraqueal, por la boca, por los ojos, por las narices, chorros que les cubrieron a los dos sin que ninguna protección sirviera. Salía con tanta fuerza que mientras convulsionaba dibujaba una serpiente roja a través del cuarto. Se apartaron espantados. En unos segundos todo acabó. Después de un silencio prolongado Jaime reaccionó:

- Vamos chicas, no había nada que hacer, daos un lavado y avisad a las auxiliares para que lo amortajen. ¿Hay familiares?

- Están avisados.

Verificó que el electrocardiograma era plano y se fue al despacho médico para leer la historia clínica. En resumen se trataba de un paciente hallado inconsciente junto al tanatorio, que presentaba una anemia severa, supuestamente por hemorragia digestiva y que es tratado en urgencias hasta estabilizarle. En la historia clínica hay una nota de banco de sangre. Se envía bolsa de reserva Duffy negativo debido a que no existe sangre compatible para el paciente.

Un dato extraño - pensó Jaime- porque esa reacción contra otras sangres sólo se ve en un defecto genético poco frecuente o en gente muy transfundida. Nombre en el DNI: Roberto Ballarín, edad 27 tacos. Nada más en la historia. Signos de hepatitis crónica en la exploración.

Una alerta se encendió en su cabeza. Jaime se dirigió a la enfermera:

— ¿Habéis sacado sangre para analítica?

— No nos ha dado tiempo.

- Hay que hacer pruebas de SIDA y hepatitis. En la urgencia le habrán sacado sangre, llamales y diles que no tiren el tubo, que lo guarden y que pasaré a recogerlo.

La otra enfermera asomó la cabeza por la puerta: 
— Jaime ha venido un familiar, dice que es su hermana.

Salió del despacho y vio a la mujer que esperaba en el pasillo con la mirada perdida y una palidez extraña que contrastaba con su traje negro.

—Buenas noches, ¿es usted familia de Roberto Ballarín? Soy el doctor Sender, pase por aquí por favor.

La mujer entró y se negó a sentarse.

- Siento darle malas noticias pero su hermano ha fallecido. Ha tenido una hemorragia masiva y no hemos podido hacer nada. Lo lamento.

La mujer seguía impasible. anemia?

— ¿No quiere sentarse? ¿Puede decirme si su hermano tenía alguna enfermedad, hepatitis o

— Mi hermano no está muerto -dijo con un tono extraño, carente de afecto-

- Mire sé que es duro admitirlo, sobre todo cuando la muerte no es esperada pero tiene que aceptarlo porque...

— Le digo que mi hermano no está muerto -y clavó su mirada furiosa- ¿Dónde está? ¿Qué han hecho con su sangre? Dijo mirando los rastros rojos que todavía llevaba marcados Jaime en la piel.

Jaime se revistió de toda la seriedad que pudo antes de hablar:

- Su hermano está siendo trasladado al mortuorio del hospital y si no me da más información sobre las enfermedades que padecía o lo que ha podido ocurrirle no tengo más remedio que ordenar una autopsia judicial porque no sabemos lo que le ha pasado.

— ¡Usted no va a hacer eso a mi hermano!

Y sin darle tiempo a responder se dispuso a salir de la habitación pero antes se volvió con lentitud y a la vez que le miraba desde un lugar extraño dijo:

- Usted es médico. ¡Usted va a curar a mi hermano!

Jaime se levantó y salió tras ella pero el pasillo se encontraba desierto.

Apareció una de las enfermeras con cara de circunstancias.

-Qué pasa ahora?

- El tubo de urgencias se ha roto en la centrífuga y en banco no les queda piloto.

- Pásame un trocar del 17, una jeringa y un tubo de EDTA que voy a por otra muestra.

— ¡Pero qué dices, si ya está en mortuorio!

- Ahí voy a recogerla.

Jaime Sender bajó a la planta menos 2 y franqueó las puertas de anatomía patológica.

Atravesó el largo pasillo en que se alineaban en botes de plástico y cristal cerebros apergaminados, hígados cirróticos, riñones quísticos y corazones infartados. Al final de la galería se acumulaban frascos con embriones y fetos malformados. Entró en el depósito y encendió las luces de neón que parpadearon blancas un instante antes de fundirse con un chisporroteo. 
Sacó la linterna de mirar gargantas y paseo su rayo marchito por las etiquetas hasta encontrar el cajón que albergaba el cuerpo de Roberto Ballarín. Sujetando la linterna con los dientes tiró del cajón y al abrirlo el cadáver bruscamente se incorporó sobre su féretro metálico babeando saliva sanguinolenta. Sender era un tipo con mucha calma pero a punto estuvo de salir corriendo. Reflexionó con frialdad, sólo podía ser un síndrome del resorte, ese que sucede en las primeras fases del rigor mortis en que los cadáveres se arquean como lagartos. Apoyó su brazo en el pecho del cadáver de Ballarín y lo puso a plano sobre el fondo del cajón de oficina siniestra. ¡Acabemos cuanto antes! Se puso la linterna en la boca y pinchó la yugular derecha. Obtuvo un líquido hemolizado que volcó en el tubo con anticoagulante.

Recubrió el cuerpo, le volvió a cerrar los ojos y cerró el cajón. A tientas se dirigió a la salida y fue entonces cuando tuvo la impresión de que alguien le vigilaba desde un lugar inalcanzable. Instintivamente dio la espalda a la oscuridad y echó a correr para salir de aquel depósito de carne dolorida. Empujó la puerta batiente y atravesó el pasillo plagado de órganos muertos hasta alcanzar la salida. No se volvió hacia el ruido de zancadas deslizantes como un batir de alas que le perseguían.. No paró de correr por los pasadizos sucios y desconchados de aquel hospital donde 3000 personas dormían, velaban o agonizaban en lucha contra algo más poderoso que ellos. Una fuerza desconocida que en esos momentos también perseguía a Jaime Sender.

Alcanzó el ascensor de urgencias y cuando las puertas se cerraban una mano pálida ya familiar se interpuso entre las dos hojas. Con un reflejo salvador clavó la aguja calibre 17 en el dorso de la mano que se retiró con un gemido. Pulsó el botón de la planta baja y corrió despavorido hacia la entrada de urgencias donde dormitaba el servicio de seguridad del Centro.

Se incorporaron asustados al ver la cara de Jaime.

- Me han querido agredir, en el mortuorio, enen la menos dos. -acertó a balbucear-

— ¡Tranquilo doctor Sender! Vamos para allá.

Jaime prefirió esperar en la urgencia, algo más calmada a las cuatro de la mañana, mientras el equipo de médicos y enfermeras le preguntaba qué había pasado. Jaime prefirió no darle importancia a lo sucedido pero derrengado en un sillón de cuero mal tapizado recobró la calma y su mente empezó a indagar sobre las posibles respuestas a aquella noche tan extraña.

Al cabo de media hora los guardias de seguridad entraron en la urgencia.

- Hemos visto huellas de sangre en la menos 2, también en la puerta del ascensor de urgencias. No había nadie, debe haber huido. ¿No le vió usted la cara?

— No - mintió Sender - Aunque en realidad no la había visto reconocería esa mano entre mil.

Sacó un café de la máquina y siguió dándole vueltas a la hipótesis disparatada que iba cristalizando en su cabeza y que era, sin embargo, la única posible. De pronto recordó los tubos que llevaba en el bolsillo de la bata y que se encontraban milagrosamente intactos. Se levantó dispuesto a resolver el misterio, porque sabía cómo hacerlo.

No sin cierta inquietud recorrió los cenicientos corredores que le llevaban a su laboratorio. Una vez allí se encerró con llave y preparó las muestras. Realizó las serologías que confirmaron infección por SIDA, Hepatitis B, C, delta y citomegalovirus. Pero la prueba definitiva aún esperaba, un análisis de ADN que respondería a la pregunta. Para amplificarlo tenía que ir a la sala de aparatos, a pocos metros del laboratorio. Abrió la puerta y escudriñó el pasillo oscuro. Por la puerta de incendios se filtraba una leve claridad. Miró el reloj, las 6 y media, pronto amanecería... Alcanzó la sala de máquinas y cerró con llave. Programó el termociclador, una fotocopiadora molecular que le diría el ADN de cuantos individuos contenía en realidad aquel ser siniestro y dejó el tubo procesándose. 
En esos momentos la sintió detrás de él. Al volverse se topó con el aliento de la que se hacía llamar hermana de Ballarín. Sostenía con una mano al ya crónicamente agonizante Roberto Ballarín que babeante y con los ojos en blanco se dirigió como una lanza hacia su cuello. Intentó evadirse pero la otra mano de su hermana aprisionó su garganta con una fuerza inhumana.

Entonces comprendió todo. Supo que no le hacía falta el resultado del termociclador para diagnosticar que aquel cuerpo era el siniestro portador de otros muchos hombres y mujeres y tal vez también de sus almas. Supo que las epidemias de SIDA y hepatitis también atacaban a esos inmortales y quizás esos virus fueran su inesperada sentencia de una muerte esta vez definitiva. Pero ante todo cuando sintió el crujido de su tráquea supo que iba a morir. Mientras su sangre era bebida por unos dientes sedientos sólo anheló con un último destello de lucidez que aquella fuera una muerte verdadera y que su espíritu no quedara prisionero, quizás el resto de la eternidad, en aquellos cuerpos impíos.

(C) 2019 por los autores; Esta obra está sujeta a la licencia de Reconocimiento 4.0 Internacional de Creative Commons. Para ver una copia de esta licencia, visite http://creativecommons.org/licenses/by-nc-nd/4.0/. 